\title{
BMJ Open Discordance between presumed standard of care and actual clinical practice: the example of rubber dam use during root canal treatment in the National Dental Practice-Based Research Network
}

\author{
Gregg H Gilbert, ${ }^{1}$ Joseph L Riley, ${ }^{2}$ Paul D Eleazer, ${ }^{3}$ Paul L Benjamin, ${ }^{4}$ \\ Ellen Funkhouser, ${ }^{5}$ National Dental PBRN Collaborative Group
}

To cite: Gilbert GH, Riley JL, Eleazer PD, et al.

Discordance between presumed standard of care and actual clinical practice: the example of rubber dam use during root canal treatment in the National Dental Practice-Based Research Network. BMJ Open 2015;5: 009779.

doi:10.1136/bmjopen-2015009779

- Prepublication history for this paper is available online. To view these files please visit the journal online (http://dx.doi.org/10.1136/ bmjopen-2015-009779).

The National Dental PBRN Collaborative Group includes practitioner, faculty, and staff investigators who contributed to this activity. A list is available at http:// nationaldentalpbrn.org/ collaborative-group.php

Received 20 August 2015 Revised 21 October 2015 Accepted 27 October 2015

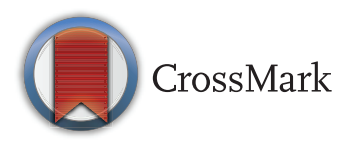

For numbered affiliations see end of article.

Correspondence to Dr Gregg H Gilbert; ghg@uab.edu

\section{ABSTRACT}

Objectives: Use of a rubber dam during root canal treatment is considered the standard of care because it enhances patient safety and optimises the odds of successful treatment. Nonetheless, not all dentists use a rubber dam, creating disconnect between presumed standard of care and what is actually done in clinical practice. Little is known about dentists' attitudes towards use of the rubber dam in their practices. The objectives were to: (1) quantify these attitudes and (2) test the hypothesis that specific attitudes are significantly associated with rubber dam use.

Setting: National Dental Practice-Based Research Network (NationalDentalPBRN.org).

Participants: 1490 network dentists.

Outcome measures: Dentists completed a questionnaire about their attitudes towards rubber dam use during root canal treatment. Three attitude scales comprised 33 items that used a 5-point ordinal scale to measure beliefs about effectiveness, inconvenience, ease of placement, comparison to other isolation techniques and patient factors. Factor analysis, cluster analysis and multivariable logistic regression analysed the relationship between attitudes and rubber dam use. Results: All items had responses at each point on the 5-point scale, with an overall pattern of substantial variation across dentists. Five attitudinal factors (rubber dam effectiveness; inconvenient/time-consuming; ease of placement; effectiveness compared to Isolite; patient factors) and 4 clusters of practitioners were identified. Each factor and cluster was independently and strongly associated with rubber dam use.

Conclusions: General dentists have substantial variation in attitudes about rubber dam use. Beliefs that rubber dam use is not effective, inconvenient, timeconsuming, not easy to place or affected by patient factors, were independently and significantly associated with lower rubber dam use. These attitudes explain why there is substantial discordance between presumed standard of care and actual practice.

\section{Strengths and limitations of this study}

Large national study of dentists who represent a diverse range of dentist characteristics, practice types and patient populations served.

- Detailed assessment of attitudes about specific clinical treatment that speaks to whether actual clinical practice conforms to a presumed standard of care.

- Single point in time based on dentist self-report.

\section{BACKGROUND}

Routinised attention to patient safety has gradually but systematically permeated healthcare, from the individual clinician, to healthcare teams, to healthcare systems at large. ${ }^{1-4}$ This is because patient safety is considered a fundamental aspect of healthcare and because the role of malpractice claims in healthcare costs has evolved. ${ }^{5-8}$ In addition to causing no harm, the competent clinician is generally regarded as one who provides care consistent with current scientific evidence and the standard of care. Although this summary applies to all fields of medicine, including dental medicine, the dental profession nonetheless provides an example in which clinicians can readily prevent an adverse patient safety event, and optimise the odds of successful treatment, yet choose not to do so.

The example has to do with root canal treatment. Root canal treatment involves (1) drilling through the biting surface of the tooth; (2) accessing the dental pulp using files to clean and disinfect the root canal system; (3) placing inert filling material in 
the canals and (4) placing a material to seal the tooth's crown. To adequately disinfect the root canal system, the dentist must avoid contamination by bacterial sources, such as the patient's own saliva. On rare occasions patients have ingested or aspirated the small instruments required to clean the canals, resulting in injury. If the dentist places a rubber dam around the tooth during endodontic treatment, then the risk of saliva contamination and ingestion of chemicals or aspiration of instruments is reduced. ${ }^{9}{ }^{10}$ Because a rubber dam ensures patient safety and optimises the odds of treatment success, its use during all root canal treatment is considered the standard of care by a professional consensus of the American Association of Endodontists (root canal specialists) ${ }^{11}$ and general dentists. A recent literature review concluded that rubber dam use is also the international standard. ${ }^{12}$ Technically, the standard of care in the USA is decided by the legal system on a case-by-case basis. ${ }^{13-15}$ However, courts usually rely on a professional consensus about what a reasonable dentist would do in a similar circumstance. Endodontic claims are among the most frequently filed malpractice claims in dentistry. ${ }^{16-18}$ In instances where a patient has ingested or aspirated an instrument, a finding of negligence by the offending dentist would be typical.

Nonetheless, use of a rubber dam during all root canal treatment is not ubiquitous. We previously reported from this study that less than half of US general dentists always use a rubber dam during root canal treatment. ${ }^{19}$ Other US and non-US studies also have documented suboptimal use. ${ }^{20} 21$ Some dentists who do not use a rubber dam instead use small cotton rolls to help isolate the tooth even though this may not do an adequate job of preventing saliva contamination and offers no protection against patient injury. Some have advocated the use of other isolation methods, such as an intraoral suctioning and retraction device called Isolite, ${ }^{22}$ although its use can only offer partial protection. Therefore, there is discordance or 'disconnect' in the dental profession between the presumed standard of care and what is done in actual clinical practice.

Unfortunately, little is known about the attitudes that general dentists have about rubber dam use and other isolation methods, and whether these attitudes are related to rubber dam use. Therefore, our objectives were to: (1) quantify these attitudes and (2) test the hypothesis that these attitudes are significantly associated with whether the dentist uses a rubber dam during root canal treatment, with other dentist and practice characteristics already taken into account.

\section{METHODS}

Dentists in the network provide an opportunity to better understand the services that dental practitioners provide. The network is a consortium of dental practices and organisations focused on improving the scientific basis for clinical decision-making. ${ }^{23}$ Many details about the network are publicly available. ${ }^{24}$

\section{Enrolment questionnaire}

The applicable network Institutional Review Boards approved the study; participants provided informed consent after receiving a full explanation of the nature of the procedures. As part of the network enrolment process, practitioners complete an enrolment questionnaire that describes characteristics about themselves and their practice(s). Questionnaire items, which had documented test/retest reliability, were taken from our previous work in a PBRN study of dental care and a network that ultimately led to the National Dental PBRN. ${ }^{25}{ }^{26}$ A copy of the questionnaire is publicly available. $^{27}$

\section{Isolation techniques questionnaire and its administration}

After confirming on the questionnaire that the respondent is a general dentist and does at least one root canal treatment each month, attitudes were measured in: (1) a section that contained 21 'agreement' statements about how strongly one agrees with certain statements, the first 12 of which examined beliefs about the effectiveness of a rubber dam, followed by nine statements about potential problems when using a rubber dam and (2) 12 'difficulty' statements about how difficult certain root canal treatment practices are. Good test/retest reliability of these items has been reported previously. ${ }^{19}$ A copy of the full questionnaire is publicly available. ${ }^{28}$ Qualitative comments were received as a result of including an item at the end of the questionnaire that asked 'Is there anything else you think we should know about how you use isolation methods during root canal treatment?', complementing the quantitative findings by providing nuanced information. Comments were received from 678 of the 1491 participants.

We have reported previously details about the survey administration. ${ }^{19}$ Briefly, 1876 dentists who reported on the enrolment questionnaire that they were a general dentist; currently practicing/seeing patients; performing at least some root canal treatment; and at least 'limited' or 'full' network participants were invited to complete the Isolation Techniques questionnaire.

\section{Statistical methods}

Analyses were done using SPSS. ${ }^{29}$ The main outcomes of interest were the frequency of use of different types of isolation techniques, with attitudes as the key predictors. A principal components analysis with orthogonal rotation was conducted separately for the 21 agreement statements and for the 12 difficulty questions as initial examination and potential factor structure, which supported the existence of multiple attitude dimensions. Items deemed appropriate from each scale were subsequently combined and a final principal components analysis was performed. Principal components were rotated to achieve an orthogonal simple structure and 
factor regression scores were saved. Factor loadings of 0.50 and greater were used for interpretation. The Kaiser-Myer-Okin statistic measured sampling adequacy for factor analysis. ${ }^{30}$

Using multivariable logistic regression, factor regression scores were used to examine the relationship between the dentist's attitudes about isolation techniques and whether these techniques were used. In addition, cluster analysis was performed using factor regression scores to identify homogenous subgroups who have similar attitudes about rubber dam as an isolation technique. An advantage of this approach is that decisions are made using a combination of attitudes and beliefs, and cluster membership is determined by each dentist's set of attitudes. Ward's clustering method, with squared Euclidean distances as the similarity measure, was used to be sensitive to differences in elevation as well as profile shape. ${ }^{31}$

\section{RESULTS}

Details on eligibility, response rates, differences between participants and non-participants, and characteristics of participants have been previously reported. ${ }^{19}$

\section{Frequency of use of rubber dam and other isolation techniques}

Only $47 \%$ reported always using a rubber dam during root canal treatment. Cotton rolls are used at least sometimes by $47 \%$ of participants and all the time by $12 \%$. Isolite was used by $8 \%(n=126)$. A total of $3 \%(n=39)$ used a method other than rubber dam, cotton roll or Isolite. Only 5\% $(\mathrm{n}=70)$ use no method of isolation. Based on the frequency distributions for each isolation technique, the following cut points were used during subsequent model testing: rubber dam use all the time ( $\mathrm{n}=697,47 \%$ of dentists); and cotton roll use at least $50 \%$ of the time $(n=283,19 \%$ of dentists $)$. Because of its infrequent use, Isolite use was not modelled.

\section{Distribution of attitudes items and factor analysis}

The wording of the attitude questions is provided in table 1 . The distributions of responses to each item are publicly available. ${ }^{32}$ With the exception of question 23 (skew $=-1.73$, kurtosis=3.0) and question 32 (skew=-2.92, kurtosis=11.43), responses to the agreement statements had skew and kurtosis of less than \pm 2 ; 16 of 21 were \pm 1 . Skew and kurtosis for the difficulty questions were all within \pm 1 and ranged from -0.66 to 0.80 for skew and -0.33 to 0.79 for kurtosis.

The Kaiser-Myer-Okin Measure of Sampling Adequacy was 0.910 for the agreement statements and 0.896 for the difficulty questions; these are very high. The 21 agreement statements formed five factors with an eigenvalue of $>1.0$. The final factor consisted of a single item (Q23-adequate training in dental school) loading higher than 0.40 . The other four factors had at least three items with loadings of 0.50 or greater. The 12 difficulty questions formed three factors, each with four items with loadings of 0.50 or greater.

Items from both scales were then combined and principal components analysis of the final pool of 31 items was done. Items Q23 and Q32 were not included because of their skewness and kurtosis. The Kaiser-Myer-Okin Measure of Sampling Adequacy was 0.936 . The rotated solution accounted for $62 \%$ of the total variance and resulted in a 5-factor solution based on eigenvalues $>1$ criterion and scree test. Factors and factor loadings are presented in table 1 . The first factor comprised 10 items from the attitude agreement scale and represented 'rubber dam is effective', accounting for $18 \%$ of the variance. The second factor comprised 10 items predominantly from the agreement attitude scale and represented 'using a rubber dam is inconvenient and time-consuming', accounting for $13 \%$ of the variance. The third factor comprised primary loadings from four items and two secondary loadings of items from the difficulty attitude scale and represented 'rubber dam is easy to place', accounting for $12 \%$ of the variance. The fourth factor comprised three items from the attitude agreement scale and represented 'rubber dam is just as effective as Isolite' and accounted for 10\% of the variance. The final factor comprised four items from the difficulty scale and represented 'patient factors do not complicate the use of a rubber dam', accounting for $9 \%$ of the variance.

\section{Logistic regression}

With the outcome as using a rubber dam all of the time, dentists who more strongly agreed that a rubber dam is effective $(p<0.001)$, who rated a rubber dam as easy to place $(p<0.001)$, and who believe that patient factors do not complicate rubber dam use $(p<0.001)$ were more likely to use a rubber dam all of the time (table 2). Dentists who agreed more strongly that using a rubber dam is inconvenient and time-consuming $(\mathrm{p}<0.001)$ or that using rubber dam is just as effective as Isolite, were less likely to use a rubber dam all of the time (table 2).

\section{Cluster analysis}

Examination of differences in potential clusters and inspection of mean factor scores for each cluster, suggested that a four-cluster solution is the most appropriate and interpretable. ${ }^{32}{ }^{33}$ Mean factor regression scores and frequencies for choice of isolation techniques for each cluster are presented in tables 3 and 4, respectively.

The first cluster comprised 252 dentists who held attitudes that rubber dam use is not effective and not easy to place. They also held the attitude that perceived patient factors 'do complicate' the use of a rubber dam. This group was least likely to use a rubber dam all the time (7\% use a rubber dam all of the time) and the most likely to use a cotton roll at least half the time (61\% of the cluster). The second cluster comprised 302 dentists who had the highest agreement on statements 


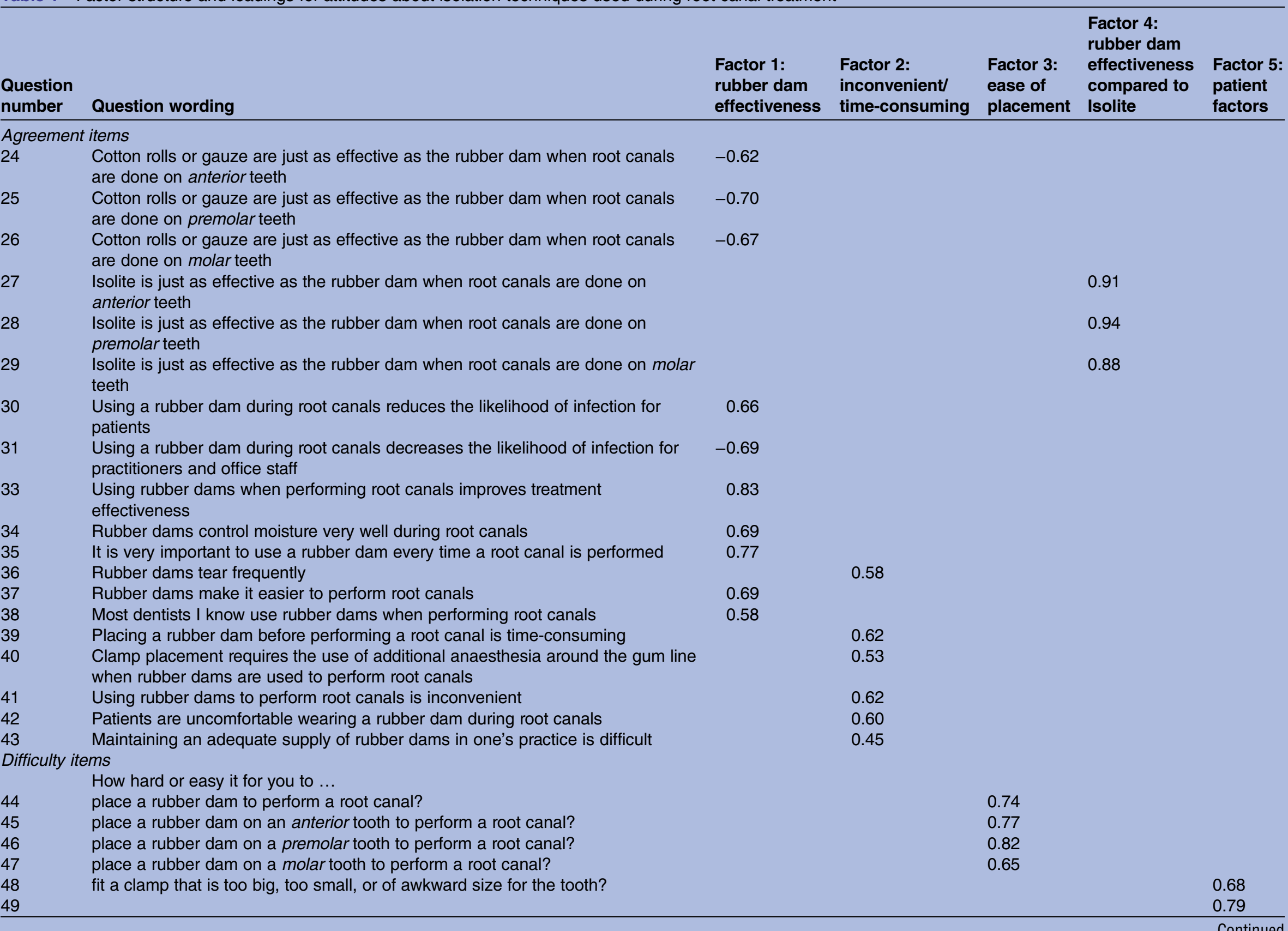




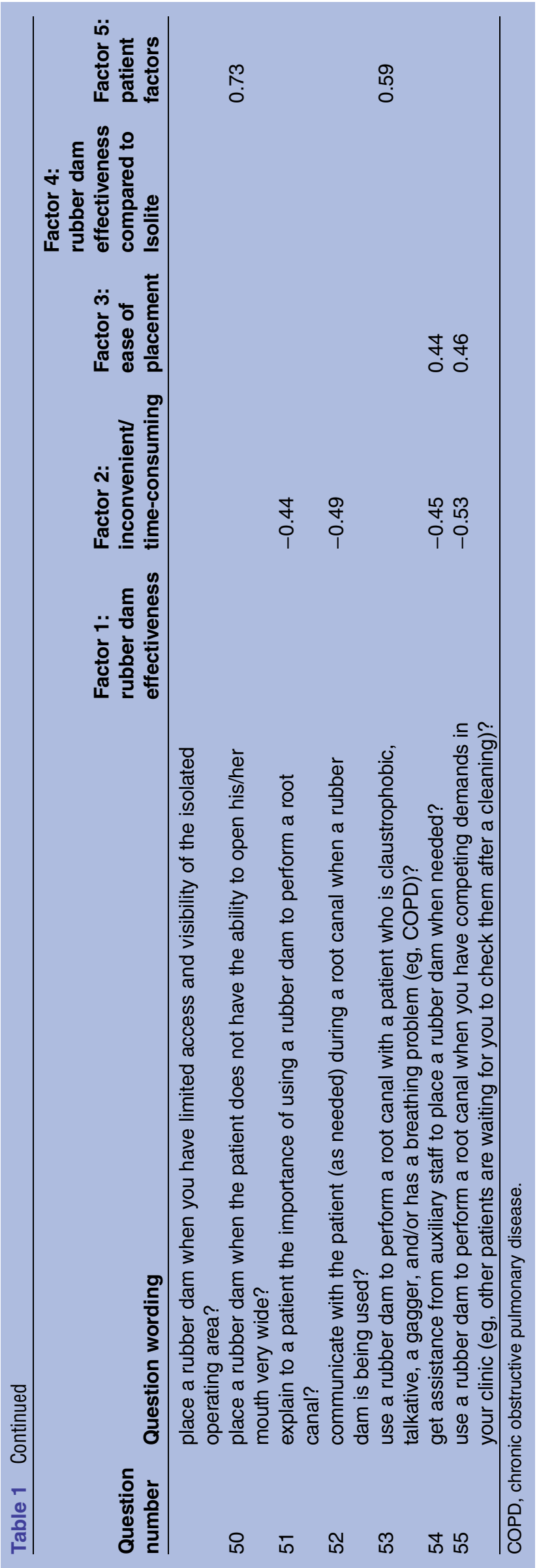

that rubber dam use is inconvenient and timeconsuming. They were near the overall mean for whether rubber dam is effective and easy to place. They also held the belief that Isolite is just as effective as rubber dam. As a group, they were second least likely to use a rubber dam $(39 \%$ use a rubber dam all of the time). The third cluster comprised 504 dentists. This group was most likely to agree with statements that rubber dam use was inconvenient and time-consuming and held the attitude that rubber dam use is effective. Nevertheless, they did believe that rubber dam can be difficult to place, but that patient factors were not the issue. This group used the rubber dam at similar frequencies to the second group (44\% use a rubber dam all of the time) and were not frequent users of a cotton roll. The fourth cluster comprised 401 general dentists, who held the attitude that rubber dam use is effective and were close to the overall mean on whether rubber dam use was inconvenient and time-consuming. This was the group who most strongly disagreed with statements that Isolite is just as effective as rubber dam. As a group, they almost exclusively used a rubber dam for root canal treatment $(82 \%$ use a rubber dam all of the time) and almost never used Isolite.

\section{DISCUSSION}

Although almost all (96\%) agreed that using a rubber dam reduces the potential for ingestion or aspiration, only $78 \%$ agreed that rubber dam use improves treatment effectiveness. This latter percentage is consistent with the minority (from $6 \%$ to $24 \%$, depending on the question, for questions 24-29) who agreed that cotton roll or Isolite use is just as effective as a rubber dam. In one of the few studies ever to evaluate dentist attitudes towards rubber dam use, a study of 300 dentists in Ireland found that only $42 \%$ agreed with the statement 'Root canal fillings placed without rubber dam isolation are as successful as when rubber dam isolation is used'. ${ }^{44}$ A study of final-year dental students at two British dental schools observed that $10 \%$ agreed with 'Root canal fillings placed without rubber dam are as successful as those isolated with rubber dam' and 68\% agreed with 'Rubber enables a higher clinical standard to be achieved'. ${ }^{35}$ Unfortunately, neither of these two studies related the attitudes to whether or not the dentist reported actually using a rubber dam or intended to. A 2009 review of the literature concluded that lack of patient acceptance and the time required to apply the rubber dam were the most common reasons. ${ }^{21}$ The same review also concluded that patient acceptance is actually very high and can be influenced substantially by the enthusiasm and experience of the dentist and dental assistant. ${ }^{21}$ We are aware of no US dental school that does not require use of a rubber dam during root canal treatment, regardless of whether the treatment is being done by a student, resident or faculty member. Our sense is that schools consider a tooth inappropriate 
Table 2 Multivariable logistic regression quantifying the relationship between dentists' attitudes and rubber dam use

\begin{tabular}{lccc} 
& Parameter estimate (SE) & $\mathbf{p}$ Value & OR (95\% Cl) \\
\hline Attitudes & & & \\
$\quad$ Rubber dam effectiveness & $1.43(0.11)$ & $<0.001$ & $4.17(3.35$ to 5.18$)$ \\
Inconvenient/time-consuming & $-0.78(0.08)$ & $<0.001$ & $0.46(0.39$ to 0.54$)$ \\
Ease of placement & $0.50(0.08)$ & $<0.001$ & $1.65(1.42$ to 1.93$)$ \\
Rubber dam effectiveness compared to Isolite & $-1.17(0.09)$ & $<0.001$ & $0.31(0.26$ to 0.36$)$ \\
Patient factors & $0.43(0.08)$ & $<0.001$ & $1.52(1.31$ to 1.76$)$ \\
Dentist and practice characteristics & & & \\
Endodontist in same building & $0.46(0.46)$ & 0.32 & $1.58(0.65$ to 3.87$)$ \\
Public health practice model (reference is large group practice) & $-1.21(0.43)$ & 0.01 & $0.30(0.13$ to 0.69$)$ \\
Private practice model (reference is large group practice) & $-1.07(0.28)$ & $<0.001$ & $0.34(0.20$ to 0.59$)$ \\
Dentist gender (male) & $-0.21(0.18)$ & 0.26 & $0.81(0.57$ to 1.17$)$ \\
Decades since dental school graduation & $-0.17(0.07)$ & 0.02 & $0.85(0.74$ to 0.97$)$ \\
Any additional training since dental school & $0.26(0.15)$ & 0.08 & $1.30(0.97$ to 1.73$)$ \\
Rural work setting & $-0.44(0.20)$ & 0.03 & $0.64(0.44$ to 0.95$)$ \\
Does fewer than 10 root canals each month & $-0.37(0.16)$ & 0.02 & $0.69(0.51$ to 0.94$)$ \\
\hline
\end{tabular}

The outcome of interest is whether or not the dentist uses a rubber dam all of the time during root canal treatment.

The regression is adjusted for differences in dentist gender (female $=0$, male $=1$ ); decades since dental school graduation truncated at $30+$ coded $(0-9=1,10-19=2,20-29=3,30+=4)$; additional training since dental school (no training=0, additional=1); practice type (large group practice $=0$, private practice $=1$, public health/government/other $=1$ ); whether the practice is located in a rural setting (urban/suburban $=0$, rural=1); whether an endodontist is located in the same building as the practice (no=0, yes=1); and whether the dentist does fewer than 10 root canal treatments each month $(10$ or more $=0,<10=1)$.

The model fit was statistically significant $\left(n=1445, \chi^{2}=802.7, p<0.001\right.$ with $\mathrm{df}=13$ ). Nagelkerke's $\mathrm{R}^{2}$ of 0.57 . The prediction success overall was $80 \%$ ( $80 \%$ for using a rubber dam all the time and $80 \%$ for not using the rubber dam all the time).

for root canal treatment if a rubber dam cannot be placed; in those cases, root canal treatment is not done and the tooth is recommended for extraction.

We conclude from the results in tables 2-4 that several key factors are associated with rubber dam use. Attitudes about rubber dam use for treatment effectiveness and patient safety, either alone or in comparison to Isolite, seem to be the main factors, with additional contributions from inconvenience, ease of use, and patient factors. These results make it clear that there is not a profession-wide consensus about the importance of rubber dam use. Regarding the patient safety issue, the profession may benefit from an effort similar to what has occurred in surgery regarding 'never events', ${ }^{4}$ which like patient ingestion or aspiration of root canal treatment instruments are rare, but nonetheless are so egregious that they warrant a routinised approach to their avoidance. Regarding treatment effectiveness, the evidence that rubber dam use improves long-term treatment effectiveness is limited, ${ }^{36}{ }^{37}$ but is it clear that to adequately disinfect the root canal system, the dentist must avoid contamination by bacterial sources, such as from the patient's own saliva. Note that the results in table 2 are also adjusted for key dentist and practice characteristics, and that most of these were also significantly associated with rubber dam use. All of these variables are modelled as main independent effects. However, it is possible that the correlation between certain main effects could also affect the results, such as a direct effect due to additional training or experience,

Table 3 Factor regression scores for each of the five attitude factors, by cluster $(n=1459)$

\begin{tabular}{|c|c|c|c|c|c|}
\hline & $\begin{array}{l}\text { Rubber dam } \\
\text { effectiveness }\end{array}$ & $\begin{array}{l}\text { Ease of } \\
\text { placement }\end{array}$ & $\begin{array}{l}\text { Inconvenient/ } \\
\text { time-consuming }\end{array}$ & $\begin{array}{l}\text { Compared } \\
\text { to Isolite }\end{array}$ & $\begin{array}{l}\text { Patient } \\
\text { factors }\end{array}$ \\
\hline $\begin{array}{l}\text { Cluster 1: Rubber dam not effective and not easy } \\
\text { to place }(n=252)\end{array}$ & -1.50 & -0.44 & 0.18 & 0.25 & -0.35 \\
\hline $\begin{array}{l}\text { Cluster 2: Rubber dam moderately effective but } \\
\text { inconvenient/time-consuming }(n=302)\end{array}$ & -0.08 & 0.14 & 0.75 & 0.63 & -0.14 \\
\hline $\begin{array}{l}\text { Cluster } 3 \text { : Rubber dam is effective but } \\
\text { inconvenient/time-consuming and not easy to } \\
\text { place }(n=504)\end{array}$ & 0.42 & -0.31 & -0.45 & 0.45 & 0.25 \\
\hline $\begin{array}{l}\text { Cluster 4: Rubber dam is effective and much } \\
\text { more so than Isolite }(n=401)\end{array}$ & 0.40 & 0.19 & -0.10 & -1.20 & 0.09 \\
\hline
\end{tabular}


Table 4 Frequency of use of isolation techniques, by cluster

\begin{tabular}{|c|c|c|c|}
\hline & $\begin{array}{l}\text { Per cent who } \\
\text { use rubber dam } \\
\text { all the time }\end{array}$ & $\begin{array}{l}\text { Per cent who use } \\
\text { cotton rolls at least } \\
\mathbf{5 0 \%} \text { of the time }\end{array}$ & $\begin{array}{l}\text { Per cent } \\
\text { use Isolite }\end{array}$ \\
\hline Cluster 1: Rubber dam not effective and not easy to place $(n=252)$ & 7 & 61 & 11 \\
\hline $\begin{array}{l}\text { Cluster 2: Rubber dam moderately effective but inconvenient/ } \\
\text { time-consuming }(n=302)\end{array}$ & 39 & 24 & 11 \\
\hline $\begin{array}{l}\text { Cluster 3: Rubber dam is effective but inconvenient/time-consuming } \\
\text { and not easy to place }(n=504)\end{array}$ & 44 & 8 & 11 \\
\hline $\begin{array}{l}\text { Cluster 4: Rubber dam is effective and much more so than Isolite } \\
(n=401)\end{array}$ & 82 & 3 & 1 \\
\hline
\end{tabular}

which then could affect the dentist's attitudes towards rubber dam use.

Although $47 \%$ of network dentists reported using a rubber dam all of the time, $16 \%$ reported using it from $90 \%$ to $99 \%$ of the time. It is possible that this latter group of dentists begins with an intention to use the rubber dam for a given patient, but decides not to if they have trouble placing it or if the patient expresses a strong desire not to have a rubber dam placed. This would be consistent with the approximate percentage of dentists who agreed or strongly agreed with the difficulties queried in the factor 5 (patient factors) items. For this reason, we repeated the multivariable logistic regression in table 2, except that the outcome of interest was rubber dam use of $90 \%$ or more, instead of all the time (results not shown, but publicly available as table $\left.\mathrm{A} 2^{32}\right)$. However, the substantive conclusions were the same.

This study does have certain limitations, and conclusions made from it should take these into account. ${ }^{19}$ Although network practitioners have much in common with dentists at large ${ }^{38}{ }^{39}$ it is possible that their root canal treatment procedures are not representative of dentists at large. Additionally, network members are not recruited randomly, so factors associated with network participation (eg, an interest in clinical research) may make network dentists unrepresentative of dentists at large. While we cannot assert that network dentists are entirely representative, we can state that they have much in common with dentists at large, while also offering substantial diversity in these characteristics. ${ }^{19}$

Results from this study can inform a next-stage intervention targeted to network members and potentially to the dental profession at large. Dissemination and scale-up approaches could be used which are targeted to practitioners who report no or low rubber dam use. ${ }^{40}$ These approaches have been used successfully in the network regarding treatment of early dental decay. ${ }^{41-43}$ The often-lamented 'research-to-practice gap' refers to the delay between what research evidence suggests should be happening in routine clinical practice, and what is actually happening. The results in this study suggest that the gap relevant to rubber dam use is a circumstance in which knowledge is available and providers are aware of it, but they have not yet implemented the recommended changes. Qualitative comments provided at the end of the questionnaire complemented the quantitative findings by providing nuanced information. For example, practitioners are generally well aware of the potential for adverse patient safety events, the potential for reduction in treatment effectiveness and the presumed standard of care. However, their retort is oftentimes their own individual clinical experience that they have not had these problems, in concert with their experience that a rubber dam can be difficult to place or not wanted by patients. Other practitioners who routinely use a rubber dam suggested that rubber dam placement is simple and that reports by other practitioners can be ascribed to insufficient training during dental school or not having dental assistants available during dental school or residency, leading them to an early but unwarranted conclusion that rubber dam use is not acceptable to patients, too difficult, or not necessary.

\section{Author affiliations}

${ }^{1}$ Department of Clinical and Community Sciences, School of Dentistry, University of Alabama at Birmingham, Birmingham, Alabama, USA

${ }^{2}$ Department of Community Dentistry and Behavioral Science, College of Dentistry, University of Florida, Gainesville, Florida, USA

${ }^{3}$ Department of Endodontics, School of Dentistry, University of Alabama at Birmingham, Birmingham, Alabama, USA

${ }^{4}$ Private practice of general dentistry, Miami, Florida, USA

${ }^{5}$ Division of Preventive Medicine, School of Medicine, University of Alabama at Birmingham, Birmingham, Alabama, USA

Acknowledgements The authors are grateful to Dr Wynne Norton, who at the time of the study was assistant professor, School of Public Health, University of Alabama at Birmingham, for her work during the development of the study protocol and questionnaire. The informed consent of all human subjects who participated in this investigation was obtained after the nature of the procedures had been explained fully. An Internet site devoted to details about the nation's network is located at http://NationalDentalPBRN.org. Persons who comprise the National Dental PBRN Collaborative Group are listed at http:// nationaldentalpbrn.org/collaborative-group.php

Contributors GHG, PDE and PLR contributed to study design and questionnaire testing. JLR and GHG conducted the analysis and review of the data and drafted the initial version of the manuscript. All authors were involved in the intellectual content and drafting of the manuscript, read and approved the final manuscript, and agree to be accountable for all aspects of the work. 
Funding This work was supported by United States National Institutes of Health grant U19-DE-22516.

Disclaimer Opinions and assertions contained here are those of the authors and are not to be construed as necessarily representing the views of the respective organizations or the National Institutes of Health.

Competing interests None declared.

Ethics approval University of Alabama at Birmingham.

Provenance and peer review Not commissioned; externally peer reviewed.

Data sharing statement No additional data are available.

Open Access This is an Open Access article distributed in accordance with the Creative Commons Attribution Non Commercial (CC BY-NC 4.0) license, which permits others to distribute, remix, adapt, build upon this work noncommercially, and license their derivative works on different terms, provided the original work is properly cited and the use is non-commercial. See: http:// creativecommons.org/licenses/by-nc/4.0/

\section{REFERENCES}

1. Bishop A, Fleming M. Patient safety and engagement at the frontlines of healthcare. Healthc Q 2014;17Spec No:36-40.

2. Berkowitz RL. Of parachutes and patient care: a call to action. Am J Obstet Gynecol 2011;205:7-9.

3. Galbraith RM, Holtman MC, Clyman SG. Use of assessment to reinforce patient safety as a habit. Qual Saf Health Care 2006;15 (Suppl 1):i30-3.

4. Mehtsun WT, Ibrahim AM, Diener-West M, et al. Surgical never events in the United States. Surgery 2013;153:465-72.

5. Mello MM, Studdert DM, Kachalia A. The medical liability climate and prospects for reform. JAMA 2014;312:2146-55

6. Wallace E, Lowry J, Smith SM, et al. The epidemiology of malpractice claims in primary care: a systematic review. BMJ Open 2013;3:pii: e002929.

7. Oyebode F. Clinical errors and medical negligence. Med Princ Pract 2013;22:323-33.

8. Institute of Medicine (US) Committee on Quality of Health Care in America. In: Kohn LT, Corrigan JM, Donaldson MS, eds. To err is human: building a safer health system. Washington DC: National Academy Press (US), 2000.

9. Tooth Morphology, Isolation, and Access Prep. In: Hargreaves KM, Berman LH, eds. Cohen's Pathways of the Pulp. 11th edn, St.Louis, MO: Elsevier, 2015

10. Fors UG, Berg JO, Sandberg H. Microbiological investigation of saliva leakage between the rubber dam and tooth during endodontic treatment. J Endod 1986;12:396-9.

11. American Association of Endodontists. AAE Position Statement: Dental Dams. http://www.aae.org/uploadedfiles/clinical_resources/ guidelines_and_position_statements/dentaldamstatement.pdf (accessed 16 Oct 2015)

12. Ahmed HM, Cohen S, Levy G, et al. Rubber dam application in endodontic practice: an update on critical educational and ethical dilemmas. Austr Dent J 2014:59:457-63.

13. McMurtrie L. Setting the legal standard of care for treatment and evidence-based medicine: a case study of antenatal corticosteroids. $J$ Law Med 2006;14:220-7.

14. Kozlick D. Clinical practice guidelines and the legal standard of care: warnings, predictions, and interdisciplinary encounters. Health Law J 2011:19:125-51.

15. Brenner LH, Brenner AT, Awerbuch EJ, et al. Beyond the standard of care: a new model to judge medical negligence. Clin Orthop Relat Res 2012;470:1357-64.

16. Givol N, Rosen E, Taicher S, et al. Risk management in endodontics. J Endod 2010;36:982-4.

17. Perea-Pérez B, Labajo-González E, Santiago-Sáez A, et al. Analysis of 415 adverse events in dental practice in Spain from 2000 to 2010. Med Oral Patol Oral Cir Bucal 2014;19:e500-5.

18. Webber J. Risk management in clinical practice. Part 4. Endodontics. Br Dent J 2010;209:161-70.

19. Lawson NC, Gilbert GH, Funkhouser E, et al, National Dental PBRN Collaborative Group. General dentists' use of isolation techniques during endodontic procedures: from the National Dental Practice-Based Research Network. J Endod 2015;41:1219-25.

20. Savani GM, Sabbah W, Sedgley CM, et al. Current trends in endodontic treatment by general dental practitioners: report of a United States national survey. J Endod 2014;40:618-24.

21. Ahmad IA. A Rubber dam usage for endodontic treatment: a review. Int Endod J 2009;42:963-72.

22. Wahl P, Andrews T. Isolation: a look at the differences and benefits of rubber dam and Isolite. Endo Practice 2010;2(3):52-5.

23. Gilbert GH, Williams OD, Korelitz JJ, et al, National Dental PBRN Collaborative Group. Purpose, structure and function of the United States National Dental Practice-Based Research Network. J Dent 2013:41:1051-9.

24. The National Dental Practice-Based Research Network, the nation's network. http://nationaldentalpbrn.org/ (accessed 15 Oct 2015).

25. The Florida Dental Care Study. http://nersp.nerdc.ufl.edu/ gilbert/ (accessed 15 Oct 2015).

26. Gilbert GH, Richman JS, Gordan VV, et al., DPBRN Collaborative Group. Lessons learned during the conduct of clinical studies in the Dental PBRN. J Dent Educ 2011;75:453-65.

27. Enrollment Page, National Dental PBRN. http://nationaldentalpbrn. org/enrollment.php (accessed 15 Oct 2015)

28. Study Results Page, National Dental PBRN, Isolation Techniques Used When Performing Root Canal Treatment section. http:// nationaldentalpbrn.org/study-results.php (accessed 15 Oct 2015) Available at http://nationaldentalpbrn.org/tyfoon/site/fckeditor/file/ IsolationTechniquesQuestionnaire-2013-12-27-V10\%200(Clean) Annotation.pdf

29. IBM SPSS Statistics 22 Documentation. IBM Software Group, Chicago, IL. http://www-01.ibm.com/support/docview.wss? uid=swg27038407 (accessed 15 Oct 2015)

30. Cerny CA, Kaiser HF. A study of a measure of sampling adequacy for factor-analytic correlation matrices. Multiv Behav Res 1977;12:43-7.

31. Overall JE, Gibson JM, Novy DM. Population recovery capabilities of 35 cluster analysis methods. J Clin Psychol 1993;49:459-70.

32. Study Results Page, National Dental PBRN. http:// nationaldentalpbrn.org/study-results.php (accessed 15 Oct 2015).

33. Milligan GA, Cooper MC. An examination of procedures for determining the number of clusters in a data set. Psychometrika 1985;50:159-79.

34. Lynch CD, McConnell RJ. Attitudes and use of rubber dam by Irish general dental practitioners. Int Endod J 2007;40:427-32.

35. Mala S, Lynch CD, Burke FM, et al. Attitudes of final year dental students to the use of rubber dam. Int Endo J 2009;42: 632-8.

36. Lin PY, Huang $\mathrm{SH}$, Chang $\mathrm{HJ}$, et al. The effect of rubber dam usage on the survival rate of teeth receiving initial root canal treatment: a nationwide population-based study. J Endod 2014:40:1733-7.

37. Goldfein J, Speirs C, Finkelman M, et al. Rubber dam use during post placement influences the success of root canal-treated teeth. $J$ Endod 2013;39:1481-4.

38. Makhija SK, Gilbert GH, Rindal DB, et al, DPBRN Collaborative Group. Dentists in practice-based research networks have much in common with dentists at large: evidence from the Dental PBRN. Gen Dent 2009;57:270-5.

39. Makhija SK, Gilbert GH, Rindal DB, et al, DPBRN Collaborative Group. Practices participating in a dental PBRN have substantial and advantageous diversity even though as a group they have much in common with dentists at large. BMC Oral Health 2009;9:26-35

40. Brownson RC, Colditz GA, Proctor EK. Dissemination and implementation research in health: translating science to practice. New York: Oxford University Press, Inc, 2012.

41. Gilbert GH, Richman JS, Qvist V, et al. Change in stated clinical practice associated with participation in the Dental Practice-Based Research Network. Gen Dent 2010;58:520-8.

42. Gilbert GH, Gordan VV, Funkhouser EM, et al. Caries treatment in a dental practice-based research network: movement toward stated evidence-based treatment. Community Dent Oral Epidemiol 2013:41:143-53.

43. Rindal DB, Flottemesch TJ, Durand EU, et al, National Dental PBRN Collaborative Group. Practice change toward better adherence to evidence-based treatment of early dental decay in the National Dental PBRN. Impl Sci 2014;9:177. 